\title{
EP-22
}

\section{Prevalence of live cancer in Indonesia: A cross sectional population-Basic Health Center (2011-2019)}

\author{
Citra SUARDI*1, Indra SUARDI ${ }^{2}$ \\ 'Department of Computer Science, Universitas Muslim Indonesia, Indonesia \\ ${ }^{2}$ Department of Midwifery, Universitas Hasanuddin, Indonesia
}

Introduction: Liver-cancer is one of the health problems in Indonesia and one of the most killers for everyone in Indonesia. The prevalence of liver-cancer in Indonesia is still high and has an increase. Impact of liver-cancer is a public health problem. Many people in Indonesia suffer from liver-cancer due to a lack of awareness of the symptoms of early detection so that cancer becomes malignant and ultimately causes death. In the later stages of liver-cancer can spread to other breasts, as well as to other body organs, such as blood vessels, lymph nodes.

Methods: The data used are secondary data from Basic Health Research since 2011 until 2019. This research is an observational study using a cross sectional design. Samples were taken from Indonesian people spread throughout Indonesia.

Results: Based on data collected from the Indonesian Ministry of Health, in 2011 cancer-related deaths totaled 2433 cases where liver-cancer became the-second number of-cancer that occurred in Indonesia. The GLOBOCAN, in 2012 liver cancer patients in Indonesia were 19.4\%. In 2015, 263,000 deaths from liver cancer were caused by hepatitis B. Until 2019, the Ministry of Health Republic of-Indonesia showed the most common cancer case in-Indonesia ware liver cancer at 12.4/100,000 population with an average death rate of 7.6/100,000 population.

Conclusions: Although the prevalence of liver-cancer has experienced and decreased, based on data obtained shows liver cancer has been the second-of-biggest cause of-death of-cancer-sufferers in Indonesia. Public health intervention is urgently needed to improve diagnosis, treatment, and early detection of liver-cancer in-Indonesia. 